\title{
En performativ museologi
}

EVA SILVÉN

Vårnumret av Nordisk Museologi 2004 nådde mig en solig dag denna förhållandevis kyliga sommar. Bakom stugan, i lä för vinden från havet, läste jag hela numret i ett svep, från början till slut. Som medlem av tidskriftens redaktionsråd kände jag redan till rubrikerna på de ingående artiklarna, dem hade redaktören i vanlig ordning sänt oss innan numret gick i tryck. Men det var som alltid lite spännande att se hur han skulle lyckas tvinna en någorlunda gemensam röd tråd genom de till synes rätt så disparata bidragen.

Redaktörens makt är stor, om den grundas på erfarenhet och ingående kännedom om ämnesområdet ifråga. Med start i den redaktionella inledningen, genom ingresserna till de enskilda artiklarna och deras inbördes ordning visade det sig att materialet än en gång hade formerats till en spegel av aktuella frågeställningar inom dagens, inte bara nordiska, museologi. Men det blev också något mer än en spegel: särskilt några texter var kritiskt uppfordrande och Per-Uno Ågrens tid som redaktör för Nordisk Museologi visade sig sluta i ett imperativt crescendo.

"Museologi och krishantering" var rubriken på numrets inledande presentation, och framför allt åsyftas det kulturpolitiska dilemma som många museer idag befinner sig i. Redaktören refererade bland annat till en föreläsning av Barbara Kirshenblatt-Gimblett, professor i Performance Studies vid New York University, och hennes tankar om en informativ respektive performativ museologi ${ }^{1}$. Med en informativ museologi avses museernas traditionella och på många sätt etablerade minneshantering medan den performativa museologin blottlägger och kritiskt utforskar den historiekonstruktion som museerna på detta vis medverkat till.

Redaktören utvecklade tankegången till att omfatta även andra slag av "museologier" och prövade dem mot numrets artiklar: ekomuseologi som en musealisering av landskapsrummet, narrativ museologi med tonvikt på berättelser och berättande, historisk museologi för studier som ökar museernas (läs de museianställdas) självkännedom. Begreppen kan diskuteras, liksom om de enskilda texterna bör kategoriseras som uttryck för den ena eller andra museologin. Poängen ligger dock i att både problematisera och operationalisera begreppen 
museologi och musealisering och det visade sig också fruktbart att ta sig igenom artiklarna med de olika "museologierna" i bakhuvudet.

\section{KUNSKAPSPROCESSER}

I tidskriftsnumrets första text, Danse macabre i musernas hus..., som också var hennes installationsföreläsning som professor i museologi vid Umeå universitet, riktar Kerstin Smeds blicken mot museernas kris i det postindustriella samhället, särskilt tydlig vid de stora gamla nationalmuseerna: "Institutionerna står i en politisk korseld mellan gamla instruktioner, som grundar sig på det nationella historiska legitimitetskomplexet, alltså att jobba med det nationella kulturarvet på det klassiska viset, och nya kulturpolitiska uppdrag som handlar om mångkulturalitet, internationellt samarbete, demokrati, främlingsfientlighet, den svagares rätt och annat. Det är där de kulturhistoriska museerna kroknar" (s 7).

Som en konsekvens av den nya situationen menar hon att museerna bör förändras från tingorienterade institutioner till funktions- och bruksorienterade "processmuseer". Som de följande artiklarna visar är det en inriktning som inte bara är önskvärd och nödvändig utan också redan praktiseras på många håll - kanske till och med ett inbyggt spänningsmoment i hela museikonstruktionen?

Även Gertrud Sæter refererar till det symboliska spänningsfält där museiverksamheten utspelar sig. I artikeln Museene mellom konservering og konsum. Nye tider og nye utfordringer for museenes verdigrunnlag og målsetting menar hon att den nya utmaningen för museerna handlar om att förstå hur de ska kunna kombinera kunskapsproduktionen med relationen till besökarna: "Museets kommunikasjon vil ikke lengre være ensidig, men den vil bygge på gjensidighet og publikums aktive deltakelse og mulighet til å oppdage og kombinere", eller med Mary F Belenky's ord: "all knowledge is constructed, and the knower is an intimate part of the known" (s 21). I den följande texten, Memory as a social and discursive practice in monuments. A case study of the Tapio Rautavad-

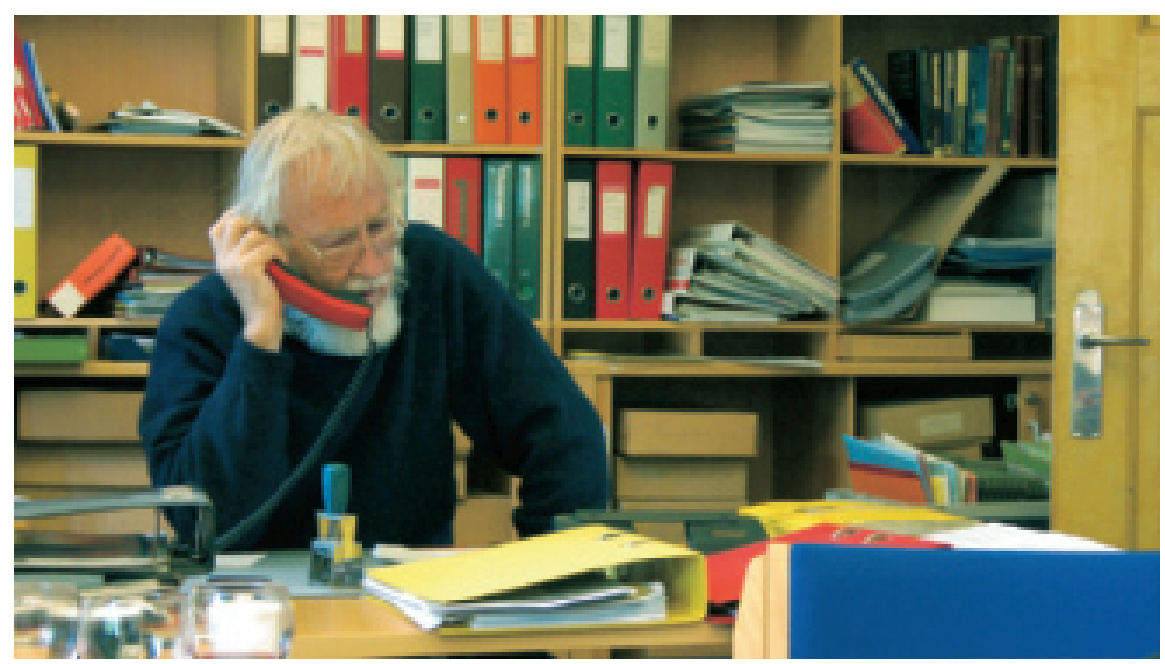

Per-Uno på Museumstjenesten $i$ Lysgård. 
ra Monument, tar Tuuli Lähdesmäki steget ut från museibyggnaden till minne och monument. Hon konstaterar att statyn över en känd finsk olympisk guldmedaljör och sångare/musiker - liksom museerna - uttrycker både nationell och lokal identitet och formar en föreställning om historien genom diskurs, performans och social praktik.

Ytterligare en process representeras av det mer eller mindre besvärande historiska arv som många museer har att hantera. Bente Gundestrup skildrar i Kunstkammeret og Albert Eckhouts malerier den vindlande väg som några föremål från museernas barndom färdats, från 1640-talets Brasilien till dagens debatt om museernas samlingar som representationer av koloniala maktrelationer.

Dessa tre texter belyser, var och en på sitt sätt, museets produktion av kunskap och värde som en fortgående process, som en performativ kulturell konstruktion, formad i samspel mellan museet och besökaren, samhället och tiden, möjlig att dekonstruera och därmed också att förändra.

\section{MitT I VERKSAMHETEN}

Härpå följer så Marc Maures Bønder, ånder, dukker og skuespillere $i$ de forste folkemuseene. ... sökte på allt sätt gifva fullt àskàdliga bilder af själva verkligheten... Med sin centrala placering mitt i tidskriftsnumret ställer den här texten de tidigare artiklarna på en historisk botten samtidigt som den krattar manegen för de följande. I snäv mening handlar artikeln om de nordiska museigrundarna Artur Hazelius, Bernard Olsens och Anders Sandvigs första utställningar. Sett i ett vidare perspektiv får vi en presentation och diskussion av det sena 1800talets museiutställningar som iscensättningar av ett nationellt kulturarv men också som mediehistoria, mellan teatern, världsutställningarna och kinematografen. Här återges dåtidens diskussioner om utställningsgestaltning mellan typologi och scenografi, om relationen mellan illusion, verklighet och autenticitet, mellan insamling och utställning, mellan kunskap, upplevelse och identifikation, om besökarens plats och roll. Samtidigt som det är en annan historisk tid än vår egen som står i fokus känns diskussionen egendomligt välbekant.

Artikeln blir på det viset ett bidrag till den kritiska analys av museernas utställningsverksamhet som under de senaste decennierna haft som mål att utveckla den performativa potentialen på bekostnad av den informativa. Artikeln blir ett exempel på att den problematik vi tycker oss stå inför inte är ny utan går att spåra långt tillbaka och kanske ligger i museernas utställningsmedium som sådant, att det snarare handlar om parallella gestaltningsformer som samtidigt konkurrerar om företrädet än en utvecklingslinje.

De följande artiklarna är av mer "informativ" karaktär och berör organisatoriskt samarbete mellan portugisiska museer, ett finskt centralmuseum för vägtrafik, bruket av digital teknik vid konservering av den norska Nidarosdomens skulpturer samt begreppet experimentell arkeologi. De vittnar om tidskriftens bredd i tid och rum och om att vetenskap och forskning $i$ museitappning inte bara är en fråga om teori utan också har en både praktisk och organisatorisk sida. För att hålla fast vid min tankegång lämnar jag dock dessa texter åsido och hoppar direkt till slutet, där tidskriftsnumrets tematiska problematik både vässas och skruvas till.

\section{DE OCH VI ANDRA}

I de sista texterna förbinds dagens postkoloniala perspektiv på museerna med den processu- 
ella och performativa aspekten. Det sker genom ett par inspirerande exempel på hur museer kan verka i sin samtid på både den sociala och kulturkritiska arenan. Två texter presenterar museet i Anacostia, Washington: Marc Maures John Kinards stemme och John Kinards To meet the needs of today's audience, från 1972. John Kinard var den förste chefen för Anacostia Neighborhood Museum som 1967 öppnade som en del av the Smithsonian Institution. Museet i Anacostia blev en del av the Black Museums Movement, som på 1970-80-talen bidrog till att förändra USA:s museilandskap. Rörelsen tog sin utgångspunkt i de svartas obefintliga representation i de amerikanska museerna men blev också en del av en större riktning med nya former som ekomuseer och grannskapsmuseer.

Inte sällan kom grannskapsmuseerna att ingå i olika sociala reformprogram, med John Kinards ord: "If museums are to meet the needs of the man of today and tomorrow, they must involve themselves in every area of human existences" (s 109), vilket i Anacostias fall blev en fråga om kriminalitet, droger, bostäder, arbetslöshet och utbildning. Under 1980-talet förändrades museet, närmiljöperspektivet tonades ner till förmån för ett bredare perspektiv på den afro-amerikanska kulturhistorien medan akademisk forskning kom att ersätta den tidigare aktionsforskningen med sin inriktning på oral history. 1987 flyttade museet till Fort Stanton Park, en mer välmående del av Washington, och efter ytterligare politiska turer kring frågan om etniskt-specifika museer borde inrättas eller inte tillskapades 1995 Anacostia Museum and Center for African American History and Culture. Kritiska röster påpekar dock att USA:s svarta fortfarande saknar ett nationellt museum vid The Mall i Washington, USA:s symboliska centrum, där the National Museum of the American Indian nu denna höst, 2004, flyttar in i en ny byggnad.

Eva Perssons efterföljande text, Det kannibaliska museet, handlar om Musée d'Etnographie de la ville de Neuchâtel (MEN) - också ett museum som tar ansvar för sin och andra museers historiska funktion i samhällets

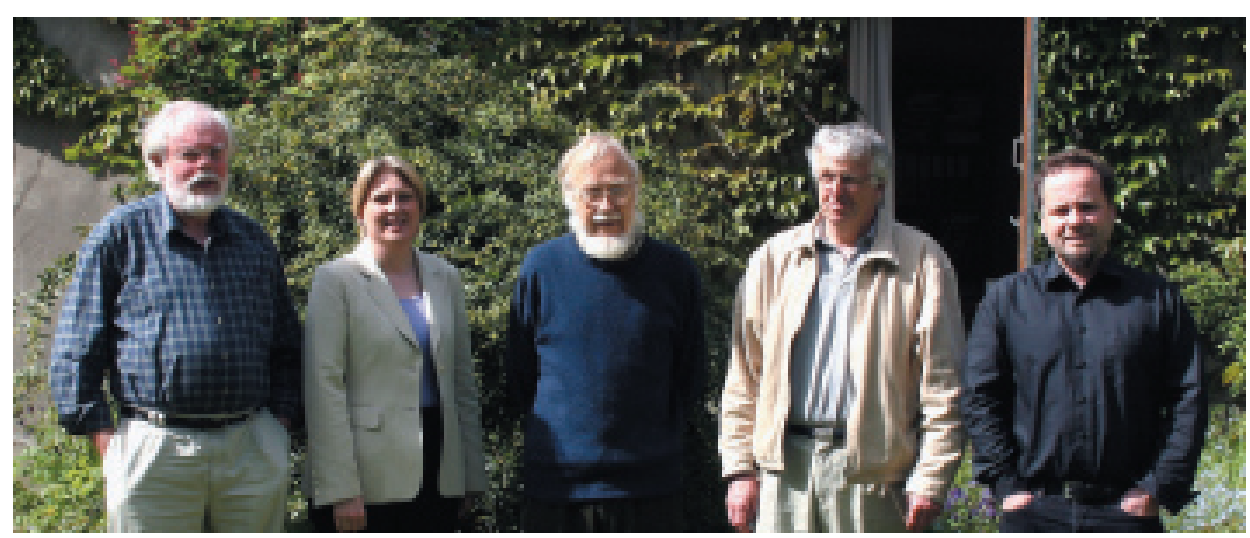

Redaktionsmode i Lysgaard den 17. maj 2004. Fra Venstre: Ole Strandgaard, Gủny Gerður Gunnarsdóttir. Per-Uno Agren, Villy Toft Jensen og Bjørnar Olsen. Janne Vilkuna var ikke til stede.

Til højre: Per-Uno besøger Nordisk Museologis trykkeri, Special-Trykkeriet i Viborg. 
maktapparat men utifrån ett helt annat perspektiv. Sedan 1989 har museet i en rad årliga temautställningar problematiserat samlandets historia och med Le museée cannibale (200203) har MEN tagit sig an museihistorien och dekonstruerat den antropologiska forskningen och museipraktiken.

Det är, menar Eva Persson, en oupphörligt överraskande utställning, som bygger på oväntade kombinationer av föremål, vilket kräver såväl djup ämneskunskap som fantasi och estetisk fingertoppskänsla: "Genom att sammanföra föremål från olika tider och olika kulturer skapar utställarna det tredje rum som postkoloniala forskare och filosofer talar om" (s 124).

Eva Persson beskriver hur hon under sin rundvandring från en överdådig festsal sugs in i en skitig och nergången förortsmiljö, vilket visar sig vara en museimonter, där hon förskräckt inser att hon själv beskådas av andra utställningsbesökare. Hon tillhör för ett ögonblick "de andra" och blir exempel på hur museets existens är beroende av att kulturerna "äter varandra”, vilket givit utställningen dess namn.
"När skall utställningskoncepten genomsyras av det reflexiva synsätt som sedan 1980-talet förnyat både den etnologiska och socialantropologiska forskningen?”, frågar Eva Persson med adress till andra museer och andra utställningsbyggare. "När inser de etnografiska museerna att det antropologiska uppdraget har förändrats och att utställningarna inte kan fortsätta leva på minnet av för länge sedan passerade storhetstider?” (s 124).

Allra sista ordet får Jacques Hainard, chef för MEN, med ett utdrag ur förordet till den första utställningskatalogen från 1989: "Museerna fortsätter att klassificera, att konkretisera och bevisa historien, men ett skifte pågår och museimannen måste på nytt pröva giltigheten i sina observationer. Det räcker inte längre att påstå, att hopa bevis i utställningar och texter, utan vi måste öppna en dialog med publiken och räkna med den på allvar. Och att tillsammans med våra besökare ställa frågor om det allmänmänskliga och att avtäcka de innebörder som förefaller samtidigt så likartade och så skiljaktiga” (s 125).

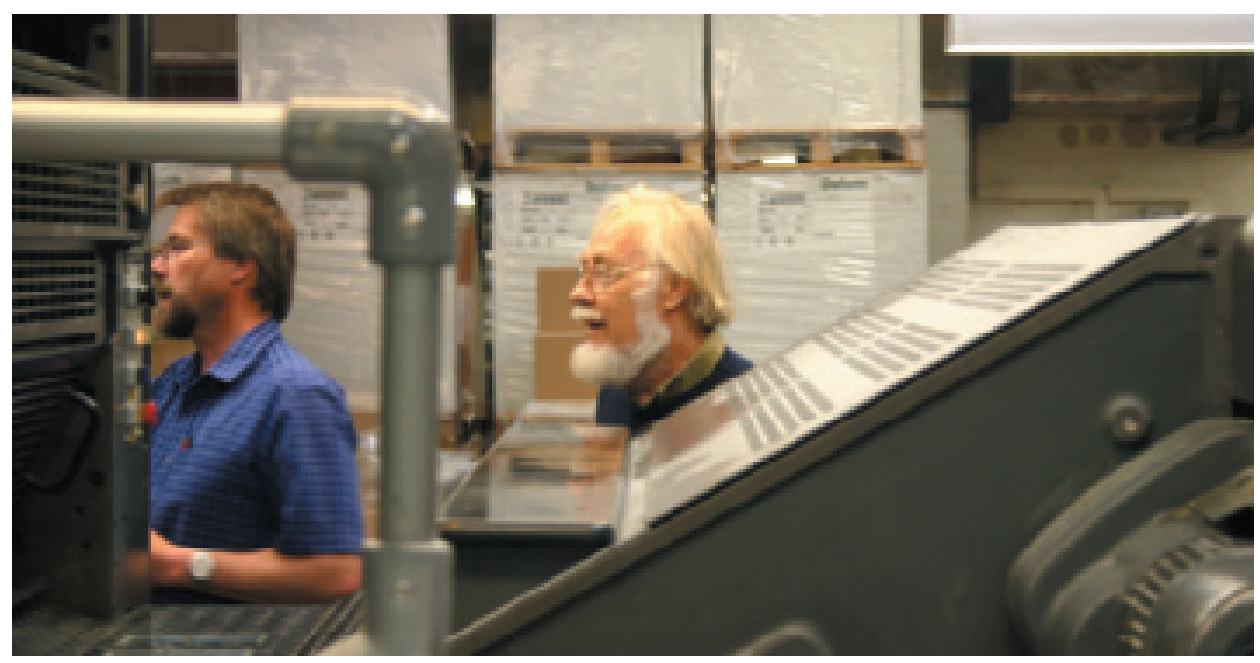




\section{EN ÖPPEN KANAL MELLAN TEORI OCH PRAKTIK}

På det här viset kan man analysera andra utgåvor av tidskriften från starten 1993 och följa hur olika frågor, problem och perspektiv passerat revy, i skilda geografiska, tidsmässiga och politiska sammanhang. (Det finns ett förträffligt kommenterat register till och med 2002, utarbetat av redaktören.) Nordisk Museologi demonstrerar behovet av ett forum för kritisk diskussion i teoretiska och metodiska museifrågor och har en viktig roll att spela för den ömsesidiga inspiration som omtalas i dess allra första nummer, nämligen att vara en "öppen kanal mellan teori och praktik" (1993:1, s 1).

Tidskriften har genom åren också bidragit till att höja blicken över de nationella frågorna, till den internationella arenan, utifrån en nordisk position. Varje lands museiverksamma behöver få perspektiv på det som står på den egna kulturpolitiska och forskningsmässiga dagordningen - i vårt svenska hörn av världen på senare år i termer av "industrisamhällets kulturarv", "mångfald" och "historiebruk". På så vis blir tidskriften som en ständigt pågående virtuell konferens, där inlägg efter inlägg fogas till olika teman som därmed blir belysta ur olika vinklar, och vilket i sin tur bidrar till att forma verksamhetsfältets frågor och problem.

Idag står frågor om minoriteters rättigheter och samhälleliga status högt på den politiska dagordningen över hela världen, vilket har satt nytt ljus på museerna. Museer har ju alltid varit verktyg för politiska syften, både uppifrån och nedifrån, och de kan bli instrument för såväl demokratiska som odemokratiska strävanden. Museers sätt att samla och beskriva, ordna och kategorisera har på olika sätt medverkat till att upprätta och upprätthålla en social ordning. Museer kan därför sägas ha makt och möjlighet att representera, att marginalisera men också att emancipera. Genom att bygga egna museer försöker olika grupper av människor ta makten över framställningen av dem själva, i såväl historien som samtiden, som i exemplet Anacostia.

Vi som antingen själva är delaktiga i eller på vetenskaplig grund intresserar oss för museerna som verktyg i samhällets sociala och kulturella processer formar en föreställd gemenskap, imagined community, av internationell räckvidd. Det är en gemenskap som snarare präglas av stimulerande konflikt än sövande konsensus men där alla är överens om att museer är fenomen värda att reflektera över. För att organisera och utveckla en sådan föreställd gemenskap krävs böcker, konferenser, webbplatser och tidskrifter - som Nordisk Museologi.

\section{SUMMARY}

\section{A performative museology}

The text is based on a reading of the latest issue of Nordisk Museologi, the last one from the retiring editor, where the museum practice is discussed in terms of process and performance. The author assserts that the journal reflects current issues of today's museology in general, not only from a Nordic point of view. But the journal is not just a mirror, some texts are crucially urgent, and Per-Uno Ågren's decade as editor ends up in a request to make better use of the museums' political and critical capacity.

\section{NOTER}

1. Barbara Kirshenblatt-Gimblett: "The Museum as Catalyst", In: Museum 2000, Per-Uno Ågren and Sophie Nyman ed. Riksutställningar, Svenska Museiföreningen and ICOM 2002.

Eva Silvén, fil dr i etnologi, intendent Nordiska museet, Box 27820, 11593 Stockholm, Sverige eva.silven@nordiskamuseet.se 